\title{
1. SANTA BARBARA BASIN EXPLANATORY NOTES ${ }^{1}$
}

\author{
Shore-based Scientific Party ${ }^{2}$
}

\section{INTRODUCTION}

In this chapter, we have assembled information that will help the reader understand the basis for our preliminary conclusions and also help investigators select samples for further analysis. This information concerns both shipboard and shore-based operations described in the Santa Barbara Basin site chapter (Site 893). Unlike other expeditions, the Santa Barbara Basin cores were split and described at the Gulf Coast Core Repository in College Station about 60 days after the completion of Leg 146.

\section{Authorship of Site Chapters}

The following scientists either wrote or made contributions to the separate sections of the site chapter (authors are listed in alphabetical order, no seniority is implied):

\author{
Site Summary: Baldauf, Kennett \\ Background and Objectives: Kennett \\ Operations: Baldauf, Foss, Kennett \\ Lithostratigraphy: Behl, Grimm, Kemp, Lange, Pratt, Schimmel- \\ mann, Stein \\ Biostratigraphy: Baldauf, Heusser, Kennett \\ Physical Properties: Rack \\ Paleomagnetism: Fuller, Lund, Olivier, Rack \\ Digital Imaging: Merrill
}

Following the text of the Santa Barbara Basin site chapter are summary core descriptions ("barrel sheets") and photographs of each core.

\section{SHIPBOARD SCIENTIFIC PROCEDURES}

\section{Numbering of Sites, Holes, Cores, and Samples}

Drilling sites are numbered consecutively from the first Deep Sea Drilling Project (DSDP) site drilled by the Glomar Challenger in 1968. A site number refers to one or more holes drilled while the ship was positioned over one acoustic beacon. Multiple holes may be drilled at a single site by pulling the drill pipe above the seafloor (out of the hole), moving the ship some distance from the previous hole, and then drilling another hole. In some cases, the ship may return to a previously occupied site to drill additional holes.

For all Ocean Drilling Program (ODP) drill sites, a letter suffix distinguishes each hole drilled at the same site. For example, the first hole drilled is assigned the site number modified by the suffix "A," the second hole takes the site number and suffix "B," and so forth. Note that this procedure differs slightly from that used by DSDP(Sites 1 through 624), but it prevents ambiguity between site- and hole-number designations. It is important to distinguish among holes drilled at a site, because recovered sediments or rocks from the same depth in

\footnotetext{
${ }^{1}$ Kennett, J.P., Baldauf, J.G., et al., 1994. Proc. ODP, Init. Repts., 146 (Pt. 2): College Station, TX (Ocean Drilling Program).

${ }^{2}$ Santa Barbara Basin group participants include Jack Baldauf, Richard Behl, William Bryant, Michael Fuller, Kurt Grimm, Linda Heusser, Alan Kemp, James Kennett, Carina Lange, Steve Lund, Russell Merrill, Fabrice Olivier, Evelyn Polgreen, Lisa Pratt, Frank Rack, Amdt Schimmelmann, Martha Schwartz, Niall Slowey, Rüdiger Stein, and Jürgen Thurow.
}

different holes do not necessarily represent equivalent positions in the stratigraphic column.

The cored interval is measured in meters below seafloor (mbsf); sub-bottom depths are determined by subtracting the drill-pipe measurement (DPM) water depth (the length of pipe from the rig floor to the seafloor) from the total DPM (from the rig floor to the bottom of the hole; see Fig. 1). Note that although the echo-sounding data (from the precision depth recorders) are used to locate the site, they are not used as a basis for any further measurements.

The depth interval assigned to an individual core begins with the depth below the seafloor that the coring operation began and extends to the depth that the coring operation ended for that core (see Fig. 1). For rotary coring using the rotary core barrel (RCB) or extended core barrel (XCB), each coring interval is equal to the length of the joint of drill pipe added for that interval (though a shorter core may be attempted in special instances). The drill pipe in use varies from about 9.4 to $9.8 \mathrm{~m}$. The pipe is measured as it is added to the drill string, and the cored interval is recorded as the length of the pipe joint to the nearest $0.1 \mathrm{~m}$. For advanced hydraulic piston coring (APC) operations, the drill string is advanced $9.5 \mathrm{~m}$, the maximum length of the piston stroke.

Coring intervals may be shorter and may not necessarily be adjacent if separated by drilled intervals. In soft sediments, the drill string can be "washed ahead" with the core barrel in place, without recovering sediments. This is achieved by pumping water down the pipe at high pressure to wash the sediment out of the way of the bit and up the annulus between the drill pipe and the wall of the hole. If thin, hard, rock layers are present, then it is possible to get "spotty" sampling of these resistant layers within the washed interval, and thus to have a cored interval greater than $9.5 \mathrm{~m}$. In drilling hard rock, a center bit may replace the core barrel if it is necessary to drill without core recovery.

Cores taken from a hole are numbered serially from the top of the hole downward. Core numbers and their associated cored intervals in meters below seafloor usually are unique in a given hole; however, this may not be true if an interval must be cored twice, because of caving of cuttings or other hole problems. Maximum full recovery for a single core is $9.5 \mathrm{~m}$ of rock or sediment contained in a plastic liner (6.6- $\mathrm{cm}$ internal diameter) plus about $0.2 \mathrm{~m}$ (without a plastic liner) in the core catcher (Fig. 2). The core catcher is a device at the bottom of the core barrel that prevents the core from sliding out when the barrel is being retrieved from the hole. For sediments, the core-catcher sample is extruded into a short piece of plastic liner and is treated as a separate section below the last core section. For hard rocks, the material recovered in the core catcher is included at the bottom of the last section. In certain situations (e.g., when coring gas-charged sediments that expand while being brought on deck), recovery may exceed the 9.5-m maximum.

A recovered sedimentary core is divided into $1.5-\mathrm{m}$ sections that are numbered serially from the top (Fig. 2). When full recovery is obtained, the sections are numbered from 1 through 7 , with the last section possibly being shorter than $1.5 \mathrm{~m}$ (rarely, an unusually long core may require more than seven sections). When less than full recovery is obtained, there will be as many sections as needed to accommodate the length of the core recovered; for example, $4 \mathrm{~m}$ of core would be divided into two 1.5 -m sections and one $1-\mathrm{m}$ section. If cores are fragmented (recovery less than 100\%), sections are numbered serially and intervening sections are noted as void, whether 


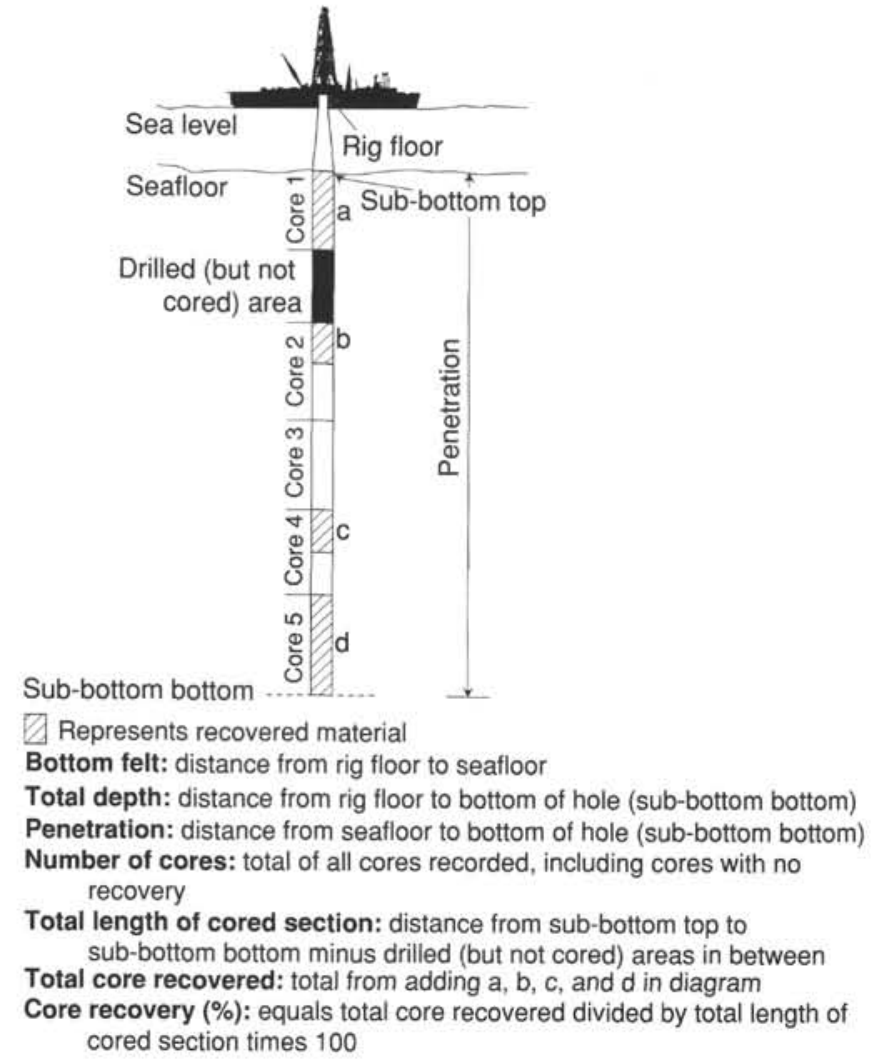

Figure 1. Diagram of terms used to discuss coring operations and core recovery.

shipboard scientists think that the fragments were contiguous in situ or not. In rare cases, a section less than $1.5 \mathrm{~m}$ may be cut to preserve features of interest (e.g., lithologic contacts).

By convention, during the process of describing the cores material recovered from the core catcher of a sedimentary core is placed in a separate section labeled core catcher (CC) below the last section recovered in the liner. The core catcher is placed at the top of the cored interval in cases where material is recovered only in the core catcher. However, information supplied by the drillers or by other sources may allow for more precise interpretation as to the correct position of core-catcher material within an incompletely recovered cored interval.

When, as is usually the case, the recovered core is shorter than the cored interval, the top of the core is equated with the top of the cored interval by convention, to achieve consistency in handling analytic data derived from the cores. Samples removed from the cores are designated by the distance measured in centimeters from the top of the section to the top and bottom of each sample removed from that section.

A full identification number for a sample consists of the following information: leg, site, hole, core number, core type, section number, and interval in centimeters measured from the top of section. For example, a sample identification of "146-893A-5H-1, 10-12 cm," would be interpreted as representing a sample removed from the interval between 10 and $12 \mathrm{~cm}$ below the top of Section 1, Core 5 (" $\mathrm{H}$ " designates that this core was taken during hydraulic piston coring) of Hole 893A during Santa Barbara operations of Leg 146.

All ODP core identifiers indicate core type. The following abbreviations are used: $\mathrm{R}=$ rotary core barrel; $\mathrm{H}=$ advanced hydraulic piston core (HPC; also referred to as APC); $\mathrm{N}=$ motor-driven core barrel (MDCB, or "Navidrill"); $\mathrm{P}=$ pressure core sampler (PCS); V $=$ vibra-percussive corer (VPC) $\mathrm{X}=$ extended core barrel; $\mathrm{B}=$ drill-bit recovery; $\mathrm{C}=$ center-bit recovery; $\mathrm{W}=$ wash core recovery; and $\mathrm{M}=$ miscellaneous material. Only APC cores were cut during the Santa Barbara operation.

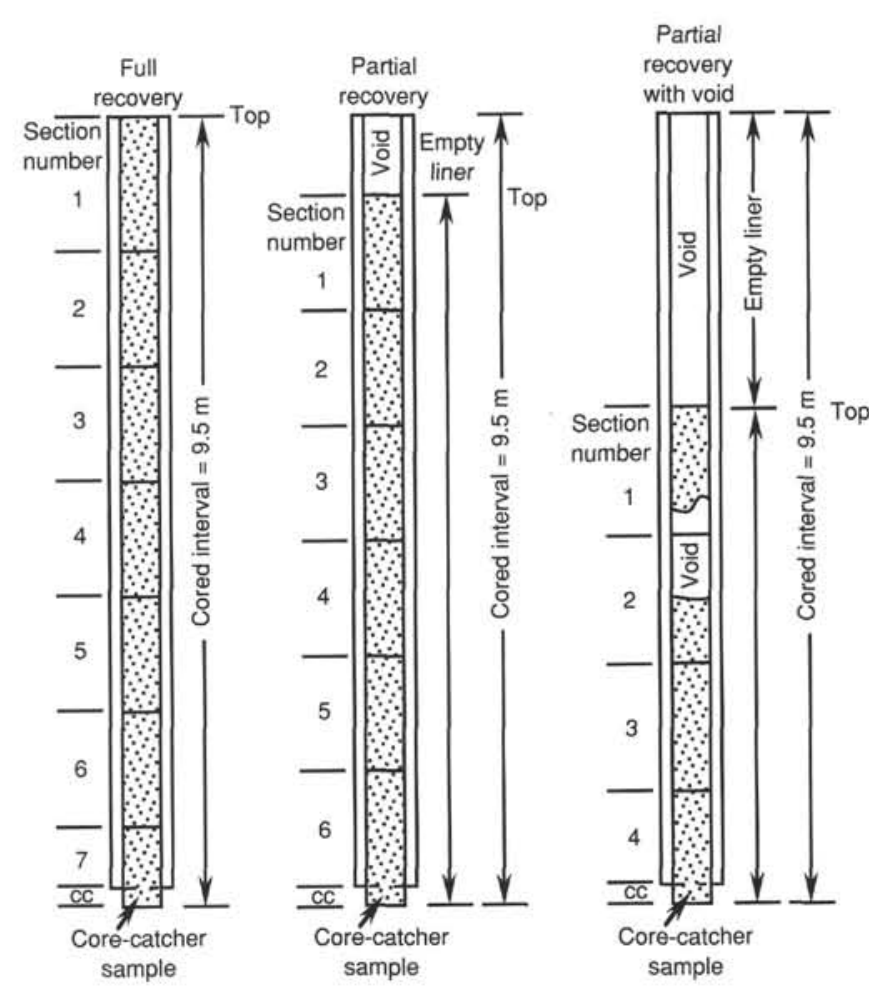

Figure 2. Diagram showing procedures used in cutting and labeling recovered core sections.

\section{Core Handling}

\section{Sediments}

As soon as a core is retrieved on deck, the core is placed on the long horizontal rack, and gas samples may be taken by piercing the core liner and withdrawing gas into a vacuum-tube ("vacutainer" method). Voids within the core are sought as sites for gas sampling. Next, the core is marked into section lengths, each section is labeled, and the core is cut into sections. Interstitial-water (IW) whole-round samples are then taken as a matter of ODP policy; whole-round samples for organic geochemistry may also be taken at this stage if they have been requested. In addition, samples for headspace gas are scraped from the ends of cut sections on the catwalk; these are sealed in glass vials for light hydrocarbon analysis. Each section is then sealed at the top and bottom by gluing on color-coded plastic caps: blue to identify the top of a section and clear for the bottom. A yellow cap is placed on section ends from which a whole-round sample has been removed, and the sample code (e.g., IW) is written on the yellow cap. The caps are usually attached to the liner by coating the end of the liner and the inside rim of the cap with acetone, and then taping the caps to the liners.

The cores then are carried into the laboratory, where the sections are again labeled, using an engraver to permanently mark the full designation of the section. The length of the core in each section and the core-catcher sample are measured to the nearest centimeter; this information is logged into the shipboard CORELOG database program.

Selected APC cores were run through the shipboard multisensor (MST) track system. The MST includes a gamma-ray attenuation porosity evaluator (GRAPE), a meter that determines the volume magnetic susceptibility, and $P$-wave logger devices which measure bulk density, porosity, and sonic velocity. Following selected MST measurements all cores were boxed as whole cores (full rounds) for shipment to the Gulf Coast Repository where each core was split, described, and sampled. 


\section{SHORE-BASED SCIENTIFIC PROCEDURES}

\section{Core Handling}

Select whole cores were run through a MST-track system at the Texas A\&M University (TAMU) Department of Oceanography. Cores were measured for magnetic susceptibility, GRAPE, and $P$-wave velocity. Following this, each core of soft material was split (with a wire) lengthwise into working and archive halves. The wire-cut cores were split from bottom to top, so investigators should be aware that older material could have been transported up the core on the split face of each section.

The working half of the core was sampled for shore-based laboratory studies. Each extracted sample was logged into the sampling computer database program by its location and the name of the investigator receiving the sample. Records of all samples removed are kept by the ODP curator. The extracted samples were sealed in plastic vials or bags and labeled.

The archive half was described visually. Selected smear slides were made from samples taken from the archive half to assist the sedimentologists in core description. The archive half was then photographed with both black-and-white and color film, a whole core at a time. All archive sections were also run through a magnetic susceptibility loop and a high-resolution color digital imaging system.

Both halves of the core were then put into labeled plastic tubes, sealed, and transferred to cold-storage space at the Gulf Coast Repository at the Ocean Drilling Program, TAMU, College Station, Texas.

\section{SHORE-BASED LITHOSTRATIGRAPHY}

\section{Sediment Core Description}

\section{Barrel Sheets}

The barrel sheets (Fig. 3) summarize the data obtained during shore-based analysis of each sediment core. These were generated using the ODP Macintosh application "VCD" (edition 1.0.1, §14). The following discussion explains the ODP conventions used in compiling each part of the core description forms, the use of "VCD" to generate these forms, and the exceptions to these procedures adopted by the Santa Barbara Basin party.

The sedimentologists were responsible for visual core logging and smear slide analyses of sedimentary material. Initial core descriptions were recorded directly on barrel sheet forms, which were then transferred to the VCD program pro-forma.

\section{Preparation of Surfaces of Core Halves for Description}

The standard method of splitting cores by cutting through the core liner and pulling a wire lengthwise through the center of the core smeared the cut surface and obscured the details of sediment lithology and structure. For example, laminations often could not be observed. The surfaces of halfcores were thus cleaned by careful scraping with a metal blade following the orientation of such sedimentary features as laminations. The scraping process was aided by charging of the blade anodically with $6 \mathrm{~V}$ DC vs. a metal spatula as a cathode. The spatula was inserted into the sediment at some distance from the anode along the side of the sediment core. The anodic charging of the anode caused the electrolytic deposition of a film of hydrogen gas on the blade's metal surface that reduced friction and further limited smearing of sediment. This procedure successfully revealed details of the sediment cores including fine laminations. Sediment from depths below $5 \mathrm{mbsf}$ had low porosity and tended to crumble when scraped with a blade. Wetting the sediment surface by spraying with ultrapure water before the scraping eliminated the problem.

\section{Core Designation}

Cores are designated using leg, site, hole, core number, and core type as discussed in a preceding section (see "Numbering of Sites, Holes, Cores, and Samples" section, this chapter). The cored interval is specified in terms of meters below sea level (mbsl) and meters below seafloor (mbsf). On the basis of drill-pipe measurements (DPM), reported by the SEDCO coring technician and the ODPoperations superintendent, depths are corrected for the height of the rig floor dual elevator stool above sea level to give true water depth and correct mbsl.

\section{Graphic Lithology Column}

The lithology of the material recovered is represented on the core description forms by up to three symbols in the column titled "Graphic Lithology" (Fig. 4). Where an interval of sediment or sedimentary rock is a homogeneous mixture, the constituent categories are separated by a solid vertical line, with each category represented by its own symbol. Constituents accounting for $<10 \%$ of the sediment in a given lithology (or others remaining after the representation of the three most abundant lithologies) are not shown in the graphic lithology column but are listed in the "Lithologic Description" section of the core description form. The graphic lithology column shows only the composition of layers or intervals exceeding $20 \mathrm{~cm}$ in thickness.

\section{Age Column}

The chronostratigraphic unit, as recognized on the basis of paleontologic criteria, is shown in the "Age" column on the core description forms. Information on the biostratigraphy is presented in the "Biostratigraphy" section of the site report. Sediments recovered from Site 893 is entirely of latest Quaternary age.

\section{Sedimentary Structures}

In sediment cores, natural structures and structures created by the coring process can be difficult to distinguish. Natural sedimentary structures observed are indicated by symbols entered in the "Structure" column of the core description forms (Fig. 5).

\section{Sediment Disturbance}

Sediment disturbance resulting from the coring process is illustrated in the "Disturbance" column on the core description forms (using symbols in Fig. 5). Blank regions indicate a lack of drilling disturbance. The degree of drilling disturbance is described for soft and firm sediments using the following categories:

1. Slightly deformed: bedding contacts are slightly bent.

2. Moderately deformed: bedding contacts have undergone extreme bowing.

3. Highly deformed: bedding is completely disturbed, sometimes showing symmetrical diapir-like or flow structures.

4. Soupy: intervals are water saturated and have lost all aspects of original bedding.

\section{Color}

The hue and chroma attributes of color were determined by comparison with Munsell soil-color charts (Munsell Soil Color Charts, 1971) as soon as possible after the cores were split and scraped because redox-associated color changes may occur when deep-sea sediments are exposed to the atmosphere. However, many of the Site 893 cores were split a few hours to days before description, losing important color information. Core photographs were made of the oxidized 


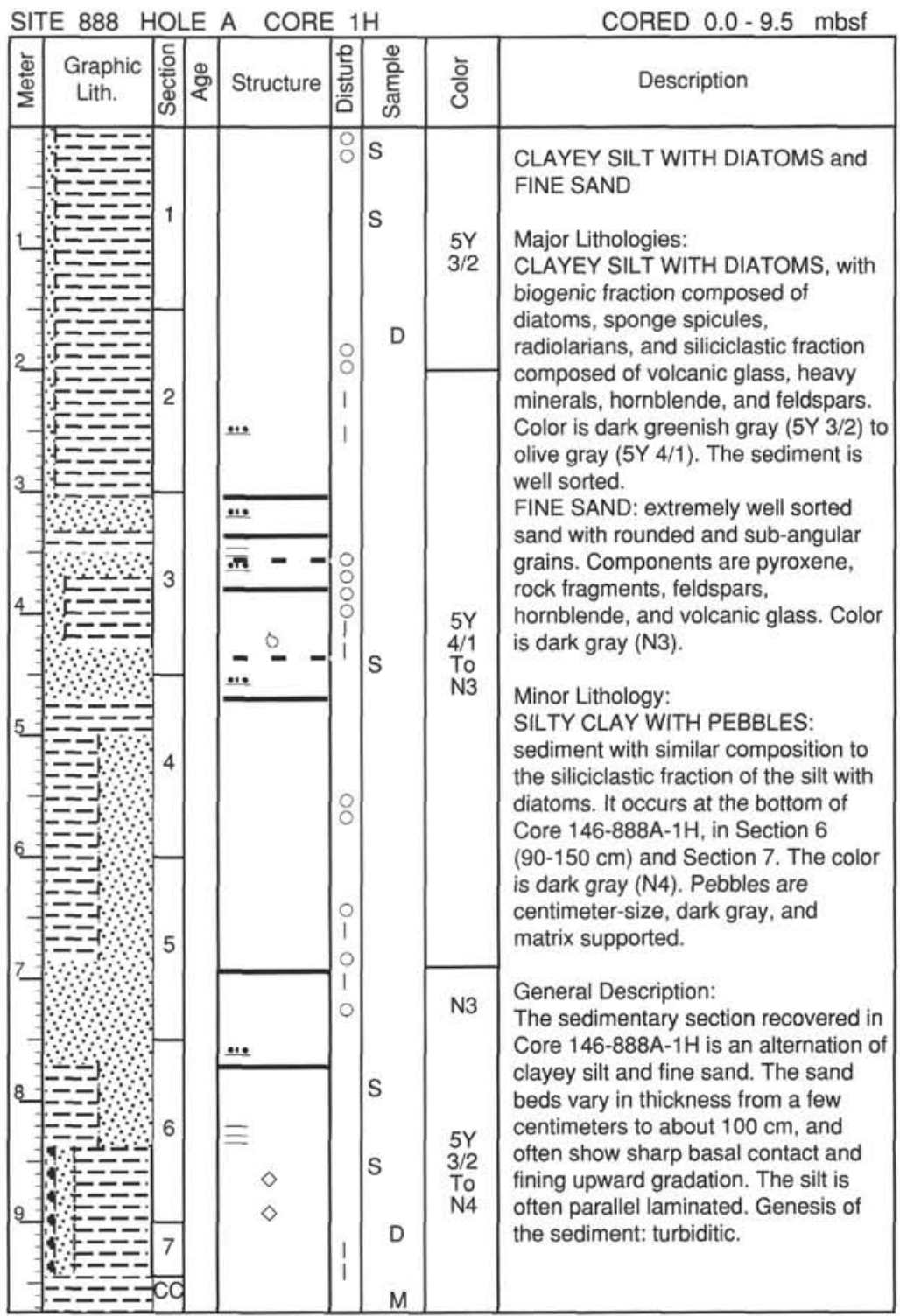

Figure 3. Core description form ("barrel sheet") used for sediment description.

surfaces that had undergone a certain amount of color change. Information on core colors is given in the "Color" column on the core description forms.

\section{Lithologic Description-Text}

The lithologic description that appears on each core description form consists of three parts: (1) a heading that lists all the major sediment lithologies (see "Sedimentology" section, this volume) observed in the core; (2) a heading for minor lithologies, and (3) a more detailed description of these sediments, including the location in the core of significant features. Descriptions and locations of thin, interbedded, or minor lithologies that cannot be depicted in the graphic lithology column are included in the text.

\section{Smear Slide Summary}

A summary of data from smear slide analyses appears as Table 2 in the "Site 893" (Santa Barbara Basin) chapter (this volume). Information presented includes the sample location, whether the sample represents a dominant ("D") or a minor ("M") lithology in the core, and the estimated percentages of sand, silt, and clay, together with all identified components. The locations of smear slide samples are indicated in the "Sample" column of the barrel sheets.

\section{SEDIMENTOLOGY \\ Classification of Sediments and Sedimentary Rocks}

The sedimentologists who described Site 893 used a modified version of the sediment classification scheme of the Ocean Drilling Program (Shipboard Scientific Party, 1990; Mazzullo et al., 1987) for granular sediment types (Fig. 6). Variations in the relative proportions of pelagic, neritic, siliciclastic, and pyroclastic grain types define four major classes of granular sediments (Fig. 6). Pelagic grains are the skeletal remains of open-marine siliceous and calcareous microfauna and microflora (e.g., radiolarians, diatoms, planktonic foraminifers, calcareous nannofossils) and associated organisms. Siliciclastic grains are mineral and rock fragments derived from igneous (plutonic and volcanic), sedimentary, and metamorphic rocks.

A granular sediment is classified by designating a principal name and modifiers. The principal name of a granular sediment defines its 
PELAGIC SEDIMENTS

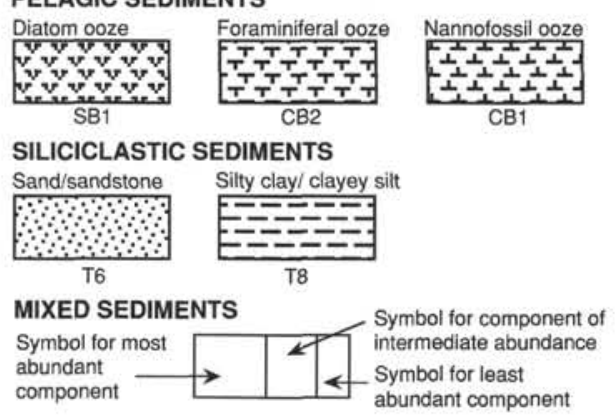

Figure 4. Key to symbols used in the "graphic lithology" column on the core description form shown in Figure 3.

granular-sediment class; the major and minor modifiers describe the texture, composition, and fabric (Fig. 6).

\section{Principal Names}

For siliciclastic sediment, the principal name describes the texture and is assigned according to the following guidelines:

1. The Udden-Wentworth grain-size scale (Wentworth, 1922; Fig. 7) defines grain-size ranges and names of the textural groups (gravel, sand, silt, and clay) and subgroups (fine sand, coarse silt, etc.) that are used as the principal names of siliciclastic sediment.

2. Principal names are listed in order of increasing abundance when two or more textural groups or subgroups are present in a siliciclastic sediment (Shepard, 1954; Fig. 8). For simplicity, we have grouped intermediate mixtures of the three textural end members (sand, silt, and clay) into four categories as shown in Figure 8 (i.e., sandy clay/clayey sand, silty clay/clayey silt, silty sand/sandy silt, and sandy silty clay).

\section{Modifiers}

The principal name of a granular-sediment class is preceded by modifiers that describe the lithology of the granular sediment in greater detail. Modifiers are used most commonly to describe composition and textures of grain types present in $>10 \%$ proportions. The composition of the biogenic components is described with the major modifiers: diatom, nannofossil, and foraminifer. The terms "siliceous" and "calcareous" are used generally to describe sediments composed of siliceous or calcareous pelagic grains of mixed origins.

Grain shapes are described by the major modifiers rounded, subrounded, subangular, and angular. Sediment color is determined with the Munsell Chart, a standard color comparator. Grain size is identified mainly through smear slides.

\section{Description of Laminated Sediments}

As laminations are a major feature of the sediments recovered at Site 893 , a special descriptive scheme has been adopted for the visual core descriptions of variations in the laminated sediment types. Three categories are adopted: "well-laminated," "indistinctly laminated," and "traces of lamination." In well-laminated sediment, laminations are generally continuous across the section of the core although some degree of disruption may be present. In indistinctly laminated sediment, laminations are highly disrupted but nevertheless clearly discernable. Where irregular remnants of laminations are present, the category "traces of laminations" is adopted.

\section{PHYSICAL PROPERTIES/PALEOMAGNETISM}

\section{Shipboard Measurements}

The cores collected at Site 893 in the Santa Barbara Basin were passed through the multisensor track (MST) on board JOIDES Resolution after allowing the minimum amount of time for thermal equilibration. The gassy condition of the individual cores prevented the

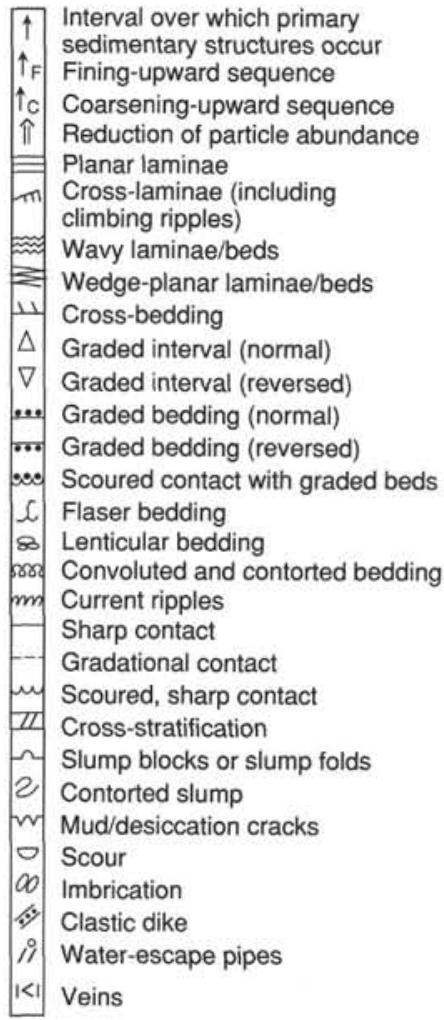

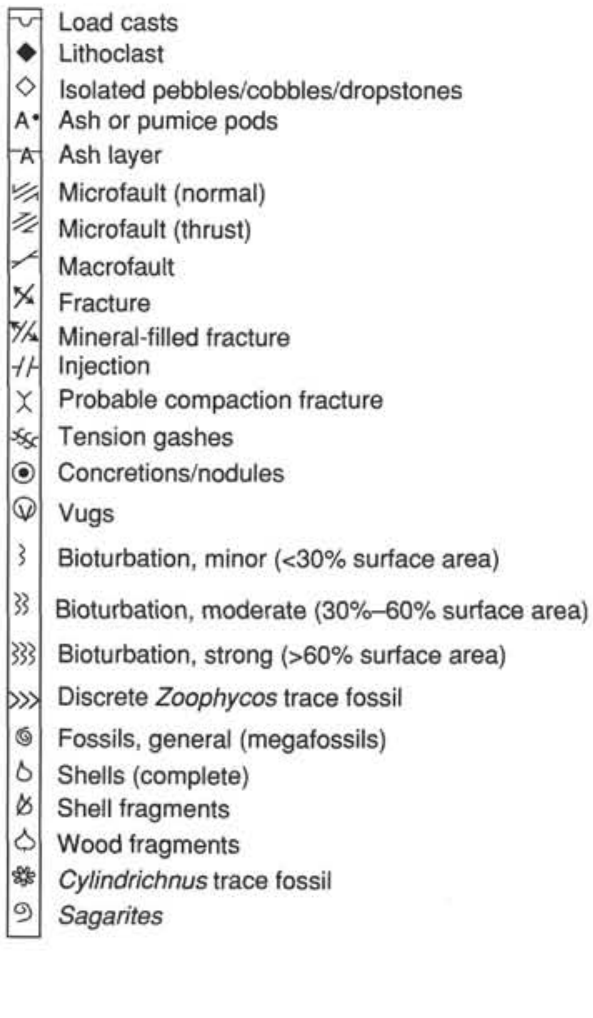

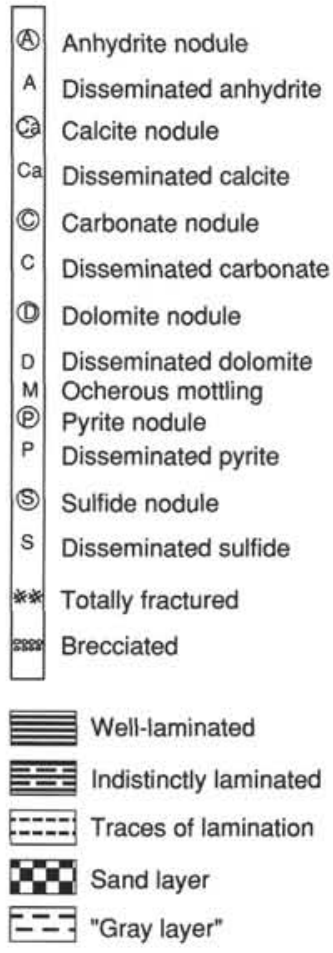

Figure 5. Symbols used for drilling disturbance and sedimentary structure on core description form shown in Figure 3. 
Ratio of siliciclastic to volcaniclastic grains

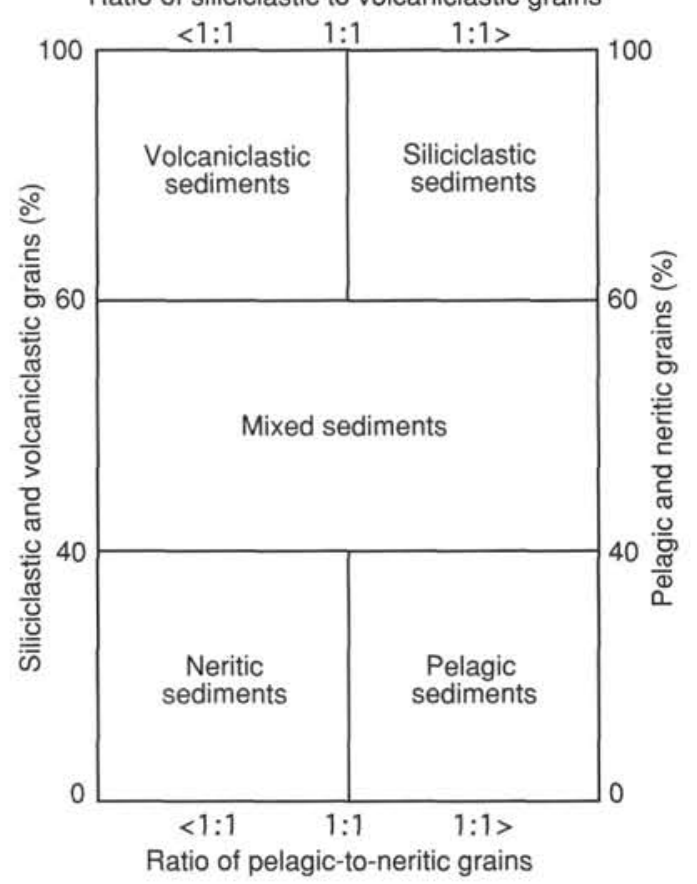

Figure 6. Diagram showing classes of granular sediment (modified from Mazzullo et al., 1987).

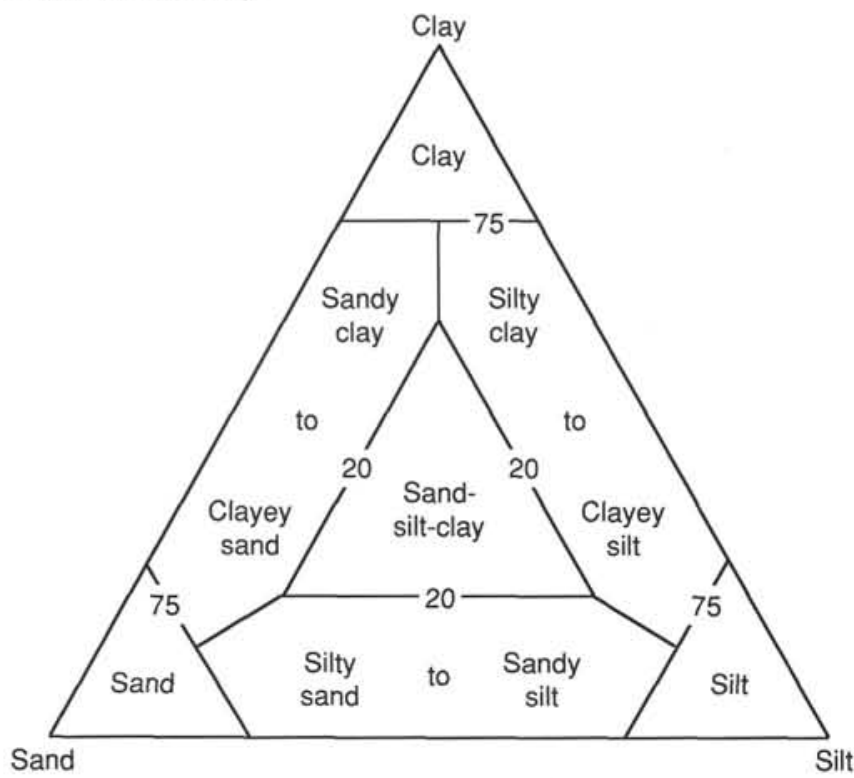

Figure 7. Udden-Wentworth grain-size scale for siliciclastic sediments (Wentworth, 1922).

collection of reliable velocity data using the $P$-wave logger (PWL) and also resulted in a large number of small to large $(<1$ to $25 \mathrm{~cm})$ voids in each section of core. Multiple small holes were drilled in the core liner of each section to release gas pressure, with only some success. These voids hindered the collection of reliable density and magnetic susceptibility data, respectively, using the GRAPE (gammaray attenuation porosity evaluator) and the Bartington MS-2 susceptibility meter (equipped with an 80-mm loop).

The GRAPE data were collected at $1-$ to $3-\mathrm{cm}$ intervals using a time step associated with the speed of the MST core boat. When the core boat remained stationary to collect magnetic susceptibility data, the GRAPE continued to collect measurements at a given position along the core. This resulted in multiple GRAPE readings at many

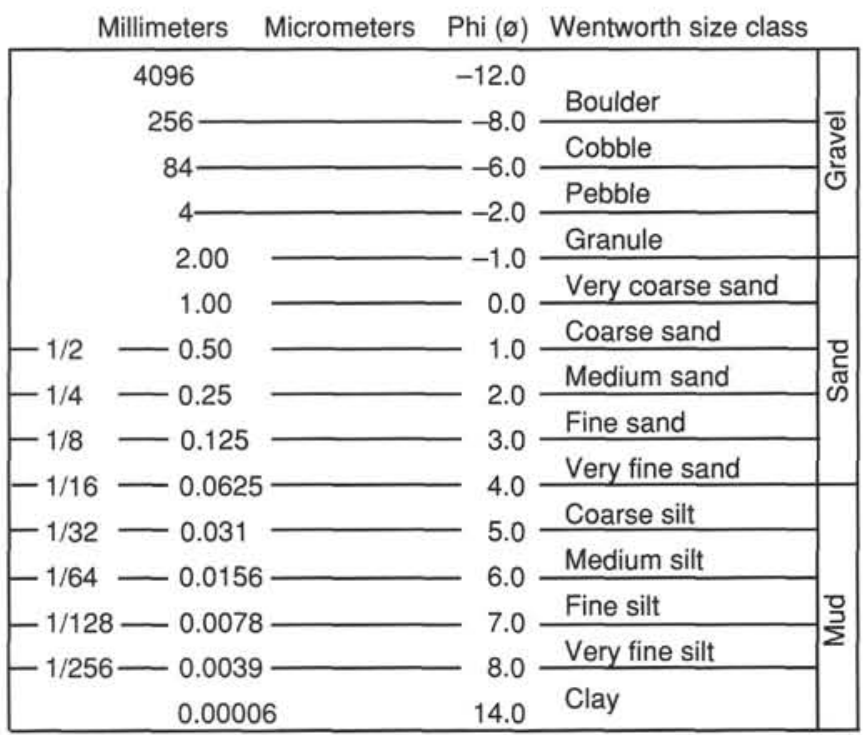

Figure 8. Ternary diagram showing principal names for siliciclastic sediments (modified from Shepard, 1954).

locations that required post-cruise processing using decimation procedures. At this time, these procedures have not been conducted; however, the GRAPE data have been smoothed using a 5-point Gaussian filter to simulate the decimation process.

\section{Shore-based Measurements}

\section{TAMU-MST}

The cores were removed from the ship during the port call in San Diego, California, and transported as whole-round core sections to the ODP Gulf Coast Repository. To compare the MST measurements collected aboard the ship with similar measurements made after transport to College Station, Texas, some whole-round core sections were passed through an MST device housed in the Department of Oceanography, TAMU. This device is configured with a $150-\mathrm{mm}$ Bartington magnetic susceptibility loop, a $P$-wave logger, and a gamma-ray attenuation device that is similar to the GRAPE. The larger diameter of the magnetic susceptibility loop results in a smoothing effect on the susceptibility signal.

Because of time constraints and the need to calibrate the newly delivered system, only a few of the core sections were measured using the TAMU-MST. These are only expected to be potentially useful for studies in Hole 893B, as the bulk of the core sections that were analyzed came from this hole.

Following the core splitting and archiving operations, the splitcore sections will be manually passed through a $100-\mathrm{mm}$ Bartington magnetic susceptibility loop to collect data at $5-\mathrm{cm}$ intervals throughout the recovered section.

\section{Discrete Measurements}

\section{Magnetic Susceptibility}

Two hundred forty two discrete samples, inside $10-\mathrm{cm}^{3}$ cylindrical plastic sample plugs, were taken at approximately $75-\mathrm{cm}$ intervals from the sediment cores collected in Hole 893A. These sample plugs were used to measure the magnetic susceptibility of the sediment and to determine their index properties (wet- and dry-bulk density, porosity, and water content) from weight and volume measurements made in a laboratory located at the ODP Gulf Coast Repository. Because of the high gas content of the sediments from this site, and the handling 
of the cores both on board JOIDES Resolution and in the lab at College Station before measuring their properties, the index properties reported here are not indicative of in-situ properties at this site. However, they are useful for identifying relative changes in sedimentary characteristics and also for determining the properties of the sediment in the laboratory at the time described.

To make the susceptibility measurements, the sample was placed inside a 36-mm (ID) loop (sensor type: MS2B) attached to a Bartington MS2 magnetic susceptibility meter and discrete measurements were made at constant settings $(0.1$ scale $=10 \mathrm{~s}$; LF). The meter was zeroed before each set of measurements, and a background measurement was taken after the removal of each sample. Because of variations in the amount of sediment in each sample cylinder, the sample plug diameter and the height of sediment within each plug were recorded, so that an approximate volume for each sample could be calculated.

A random collection of 50 empty plastic sample plugs were measured to determine the average magnetic susceptibility of the containers housing the sediment samples. This value was found to be \pm 0.2 (SI units).

\section{Index Properties}

A number of samples were selected for index properties determinations at approximately $1-$ to $5-\mathrm{m}$ sample spacings. The method of extracting samples from the core using the cylindrical plastic sample plugs resulted in variable sample volumes because of the difference in the height of the sample in the cylinder. The wet sample volume was calculated using the formula for the volume of a cylinder (sample volume $\left.=2 \Pi r^{2} h\right)$. The diameter of each sample plug is equal to $2.2-2.1 \mathrm{~cm}$ with a slight taper; therefore, two values of sample volume were calculated for each sample cylinder $(\mathrm{vol} / 1=2.2 \mathrm{~cm}$ diameter, $\mathrm{vol} / 2=2.1 \mathrm{~cm}$ diameter). Ideally, the magnetic susceptibility values should be normalized to a constant volume or constant mass. The normalized data will be included the Scientific Results volume for Site 893.

The wet weight of each sample and plastic plug (in grams) was determined by means of a Sartorius electronic balance immediately after completing the magnetic susceptibility measurements for each core. Subsequently, the samples were freeze dried for 24-36 hr, and then the weight of the dry sample and plastic plug, and the weight of the empty plastic sample plug, were determined. A split of each sample was taken to determine the calcium carbonate content using a Coulometrics coulometer located in the Gulf Coast Repository.

The wet and dry weights and wet sample volumes were used to calculate the index properties using standard ODP equations and constants (see ODP Data File Documentation, August 1989, Physical Properties Measurements), as follows:

\section{Wet-bulk density $($ WBD $)=$}

(sample wet weight/sample wet volume),

$$
\text { Dry-bulk density }(\mathrm{DBD})=
$$

(sample dry weight - salt)/sample wet volume,

$$
\text { Porosity }=\frac{(100 \cdot \text { corrected water weight })}{(\text { water density }) \cdot(\text { sample wet volume })},
$$

Wet water content $=\frac{(100 \cdot \text { corrected water weight })}{\text { sample wet weight }}$,

$$
\text { Dry water content }=\frac{(100 \cdot \text { corrected water weight })}{(\text { sample dry weight })-(\text { salt })} \text {, }
$$

\author{
Corrected water weight $=$ \\ $\frac{\text { (sample wet weight) }- \text { (sample dry weight) }}{0.965}$, and
}

$$
\text { Salt }=0.035 \cdot(\text { corrected } \text { water weight })
$$

A limited number of samples were set aside for index properties determinations using a Penta Pycnometer, which was available at ODP, to check on the accuracy of these procedures. The samples that were to be measured in the pycnometer were placed into beakers of known weight and volume and then the wet weight of the sample and beaker was determined. These pycnometer samples were then oven dried at $110^{\circ} \mathrm{C}$ for $24 \mathrm{hr}$ before determining the dry weight and volume of each sample. These data were used to calculate the void ratio, porosity, water content, and grain density of each sample. Only the dry volume of each sample was determined in the pycnometer, so the following additional equations were used to calculate these properties (see ODP Data File Documentation, August 1989, Physical Properties Measurements).

$$
\begin{aligned}
& \text { Grain density }=\frac{(\text { sample dry weight })-(\text { salt })}{(\text { sample dry volume })-(\text { salt } / \text { salt density })}, \\
& \text { Void ratio }= \\
& \text { corrected water weight } \\
& \overline{\text { water density } \cdot[(\text { sample dry volume }- \text { salt }) /(\text { salt density })]} \text {, } \\
& \text { Porosity }=\frac{\text { void ratio }}{(1+\text { void ratio })} \text {, and }
\end{aligned}
$$$$
\text { Decimal porosity } \cdot 100=\text { percent }(\%) \text {. }
$$

A corrected depth scale is required to correct for the void spacing in the cores from this site; however, the discrete data has been plotted using the uncorrected sub-bottom depths in order to show general downhole trends.

\section{Color Digital Imaging}

A high-resolution color image was captured of each 10-cm interval of the split core, overlapping at both ends of each interval, so that each image covers a $13.5-\mathrm{cm}$ piece of core. Image resolution is 1008 $\times 486$ pixels, so each pixel spans about $134 \mu \mathrm{m}$ along the length of the core and $210 \mu \mathrm{m}$ along the diameter. Pixel depth was set to 16 bits. The image capture process required roughly 2 weeks to complete, so core surfaces were oxidized thoroughly before being imaged.

The ODP color digital imaging system that captured these images incorporates a Sony DXC-750MD camera equipped with three CCDs, so that red, green, and blue images are captured simultaneously, and a Fujinon TV.Z $4 \times 7.5$ lens. Capture was performed by a Truevision AT-Vista 4M video capture board mounted in an IBM 386/33 clone. The color temperature of the light source (filtered tungsten) was $5020^{\circ} \mathrm{K}$. Measurements of light actually incident upon samples ranged between $4300^{\circ}$ and $4600^{\circ} \mathrm{K}$, and demonstrated that intensity was uniform throughout the sample area. Images were stored in extended TGA (TGA 2.0) format on magneto-optical discs, and later were transferred to ISO-9660 compatible CD-R discs for archival storage.

Calibration standards consisted of the Kodak Color Separation Guide and Gray Scale (CAT 152 7654) and a set of standard color chips supplied by MacBeth that were also captured on a regular schedule, interspersed among core images. Images of a full suite of British Ceramic Research Association (BCRA) Ceramic Color Standards, 
calibrated by the Hemmendinger Color Lab, were captured as well. Color reflectance properties of these materials are well understood; therefore, they may be used as standards for a variety of measurements.

\section{BIOSTRATIGRAPHY}

\section{Microfossils}

During Site 893 shipboard operations, core-catcher samples were taken for foraminifers, diatoms, radiolarians, calcareous nannofossils, and pollen. Preliminary analyses of these samples have been completed for foraminifers, pollen, and diatoms. Foraminiferal samples were dried, disaggregated in warm water, and washed over a $63-\mu \mathrm{m}$ sieve. The coarse $(>63 \mu \mathrm{m})$ residue was retrieved and examined for foraminifer content. Pollen samples were processed using standard techniques modified for isolating pollen from marine sediments (Heusser and Stock, 1984). For this preliminary survey, pollen percentages were based upon counting 100 pollen grains per sample. Reference collections from regional vegetation and published sources were used to verify pollen identification. Spores and palynomorphs such as dinoflagellates, as well as charcoal fragments, were calculated outside the basic pollen sum. A standard unit of exotic spores was added to each sample. Pollen concentration (grains/gdws) was calculated using the ration of indigenous pollen to the number of exotic spores per unit volume.

\section{REFERENCES*}

Heusser, L., and Stock, C., 1984. Preparation techniques for concentrating pollen from marine sediments and other sediments with low pollen density. Palynology, 8:225-227.

Mazzullo, J.M., Meyer, A., and Kidd, R., 1987. New sediment classification scheme for the Ocean Drilling Program. In Mazzullo, J., and Graham, A.G. (Eds.), Handbook for Shipboard Sedimentologists. ODP Tech. Note, 8:45-67.

Munsell Soil Color Charts, 1971. Baltimore, MD (Munsell Color).

Shepard, F., 1954. Nomenclature based on sand-silt-clay ratios. J. Sediment. Petrol, 24:151-158.

Shipboard Scientific Party, 1990. Explanatory notes. In Rangin, C., Silver, E.A., von Breymann, M.T., et al., Proc. ODP, Init. Repts., 124: College Station, TX (Ocean Drilling Program), 7-33.

Wentworth, C.K., 1922. A scale of grade and class terms of clastic sediments. J. Geol., 30:377-392.

\footnotetext{
Abbreviations for names of organizations and publication titles in ODP reference lists follow the style given in Chemical Abstracts Service Source Index (published by American Chemical Society).
}

Ms 146IR-023 